\title{
The predictive factors that are associated with the number of sutures used during meniscal repair
}

\author{
Xiaoxiao Song ${ }^{1}$, Dongyang Chen², Xinsheng Qi ${ }^{1}$, Qing Jiang ${ }^{2}$ and Caiwei Xia ${ }^{1 *}$
}

\begin{abstract}
Purpose: To investigate factors associated with the consumption of a large number of sutures during arthroscopic meniscus repair procedures.

Methods: All patients who received meniscal repair, with or without concomitant anterior cruciate ligament (ACL) reconstruction, in our hospital from January 2015 to December 2019 were included in the current study. Demographic data (sex, age, body mass index (BMI), and injury-to-surgery interval) and surgical data (the site of the tear, side of the meniscus, presence of an $\mathrm{ACL}$ rupture or not and the number of sutures) were retrospectively collected from our medical records. The number of sutures was divided into two groups (1-2 sutures versus $>2$ sutures). The stitching process was implemented through an all-inside technique using a meniscal repair device (Fast-Fix; Smith \& Nephew). According to the length and stability of the meniscal tear, one to seven sutures were used. Univariate analysis consisted of chi-square tests. Multivariate logistic regression was then performed to adjust for confounding factors.
\end{abstract}

Results: A total of 242 patients, including 168 males and 57 females, was finally included. In the univariate analysis, we found that those patients who underwent meniscus repair within one month after meniscus tear were more likely to need fewer sutures than those who underwent surgery more than one month after injury (70/110 versus 59/115, $p=0.062)$. In total, 75/109 (68.8\%) lateral meniscal tears were repaired with fewer sutures than medial $(34 / 72,47.2 \%)$ and bilateral meniscus injuries (20/44, 45.4\%; $p=0.003)$. In the multivariate analysis, we found that the duration of injury (OR, 2.06; $95 \% \mathrm{Cl}, 1.16-3.64, p=0.013)$, presence of an $\mathrm{ACL}$ injury $(\mathrm{OR}, 3.76 ; 95 \% \mathrm{Cl}, 1.97-7.21$, $p<0.001)$ and the side of the meniscus $(\mathrm{OR}, 0.31 ; 95 \% \mathrm{Cl}, 0.14-0.65, p=0.002)$ were associated with the number of sutures used during meniscal repair procedures.

Conclusions: Patients who underwent meniscal repair within one month after meniscus tear, especially lateral menisci tears, were more likely to need fewer sutures.

Study design: Case-control study; level of evidence, 3.

Keywords: Meniscal repair, Sutures, Concurrent ACL injury, Lateral, Duration of injury

\footnotetext{
* Correspondence: njusummer@163.com

'Department of Orthopedics, Affiliated Taikang Xianlin Drum Tower Hospital,

Medical School of Nanjing University, Nanjing, Jiangsu, People's Republic of

China

Full list of author information is available at the end of the article
}

(c) The Author(s). 2021 Open Access This article is licensed under a Creative Commons Attribution 4.0 International License, which permits use, sharing, adaptation, distribution and reproduction in any medium or format, as long as you give appropriate credit to the original author(s) and the source, provide a link to the Creative Commons licence, and indicate if changes were made. The images or other third party material in this article are included in the article's Creative Commons licence, unless indicated otherwise in a credit line to the material. If material is not included in the article's Creative Commons licence and your intended use is not permitted by statutory regulation or exceeds the permitted use, you will need to obtain permission directly from the copyright holder. To view a copy of this licence, visit http://creativecommons.org/licenses/by/4.0/. The Creative Commons Public Domain Dedication waiver (http://creativecommons.org/publicdomain/zero/1.0/) applies to the data made available in this article, unless otherwise stated in a credit line to the data. 


\section{Background}

The meniscus is the second stabilizer in the knee joint and can slow the progression of osteoarthritis (OA) by absorbing shock and transmitting load [1-3]. When meniscal tearing occurs, there are three options: nonoperative treatment, partial or total meniscectomy and meniscal repair. Nonoperative treatment has been regarded as an important choice to relieve knee pain and improve function, especially in patients with degenerative tears [4]. However, when the meniscal injury is serious such as bucket-handle tears or nonoperative treatment fails, an arthroscopic procedure must be performed. Many observational studies have demonstrated that meniscectomy can dramatically improve pain and knee function at short-term follow-up, but the loss of meniscal tissue also leads to the onset of early osteoarthritis $[5,6]$. Compared with meniscectomy, meniscal repair can preserve meniscal tissue, thus restoring its biomechanical function and reducing the risk of developing knee $\mathrm{OA}$ in the future.

In the above setting, a consensus has been reached that meniscal tissue should be preserved as much as possible $[1,7,8]$. The decision as to whether to repair the injured meniscus is made by the surgeon. The indications for repair that surgeons usually consider include (1) the location of the meniscal tear and whether vascularity is adequate enough to enhance the rate of healing of the meniscus, and (2) the severity of the meniscal injury and whether the remaining meniscal tissue is adequate to make the repair viable [9].

The number of sutures is usually affected by the length of the meniscal tear. Theoretically, the longer the tear, the more sutures will be used $[10,11]$. Patients often consult about the fee for the meniscal repair procedure preoperatively, but the surgeons cannot give them an accurate answer as it depends on the number of sutures, which are relatively expensive (560 dollars for one suture). Recently, in a study performed by John et al. [12], a greater number of sutures had been showed to be associated with a lower failure rate. Besides, the number of sutures indirectly reflect the length of meniscal tears which have been demonstrated to be a predicting factor of high failure rate of meniscal repair [2, 13]. Thus, we performed this study to investigate factors that are associated with a larger number of sutures so that we can inform patients about the probable surgical cost before surgery. Additionally, identifying these factors can also help surgeons to make surgical planning and counselling about prognosis preoperatively.

\section{Method}

Institutional review board approval was waived. In the current study, 242 patients received meniscal repair, with or without concomitant anterior cruciate ligament
(ACL) reconstruction, in our hospital from January 2015 to December 2019. All operations were performed by three highly experienced surgeons using a uniform procedure.

Demographic data (sex, age, body mass index (BMI), and injury-to-surgery interval) and intra-articular-related data (the site of the tear, the side of the meniscus, presence of an ACL rupture or not and the number of sutures) were retrospectively collected from our medical records. The injury-to-surgery interval was divided into an early group ( $\leq 1$ month) and a delayed group ( $>1$ month). Age was classified into an older group ( $>40$ years) and a younger group ( $\leq 40$ years), and BMI was classified into three groups $\left(\leq 24 \mathrm{~kg} / \mathrm{m}^{2}, 24-27 \mathrm{~kg} / \mathrm{m}^{2}\right.$, and $\geq 27 \mathrm{~kg} / \mathrm{m}^{2}$ ). The number of sutures was classified into two groups (1-2 sutures versus $>2$ sutures).

All cases of meniscal tears were diagnosed via physical examination and magnetic resonance imaging (MRI) and confirmed by arthroscopic findings. Standard anterolateral and anteromedial knee portals were used for all patients undergoing meniscal repair under general anesthesia. After completion of diagnostic arthroscopy, a few steps were taken to repair meniscus. First, the meniscal disorder was defined, then both edges of the tear were trimmed and refreshed. Final, a meniscal repair device (Fast-Fix; Smith \& Nephew) was used to finish the stitching process through an all-inside technique. According to the length and stability of the meniscal tear, one to seven sutures were used. If patients had a concomitant ACL rupture, ACL reconstruction would be performed using tendon of peroneus longus through an independent femoral approach fixed with a bioabsorbable interference screw as previously described [14].

An angle adjustable brace was used for all patients until 6 weeks after surgery. The angle of knee flexion was less than 45 degrees within 2 weeks after meniscal repair, 90 degrees within 4 weeks, and 120 degrees 6 weeks later and reach a similar angle as the uninjured side 8 weeks later after operation. Partial weightbearing was allowed until 4 weeks after surgery with the help of a crutch, and total weightbearing was encouraged 6 weeks after the operation.

\section{Statistical analysis}

Statistical analyses were performed with SPSS, version 23.0 (SPSS Inc., Chicago, IL, USA). In the univariate analysis, we used the chi-squared test to describe the associations between categorical variables and the number of sutures used during meniscal repair. Risk factors with a $p$ value less than 0.1 in the univariate analysis were used in the multivariate analysis. In the multivariate analysis, we used binary regression to determine the independent risk factors for a larger number of sutures. Odds ratios and 95\% confidence intervals (CIs) were 
reported. A $p$ value less than 0.05 indicated statistical significance.

\section{Results}

In the current study, 242 patients, including 168 males and 57 females, with a mean age of 28.3 years (range from 10 to 63 years) who underwent meniscal repair in our hospital from January 2015 to December 2019 were included. Of these patients, 188 underwent concomitant ACL reconstruction, and 37 underwent isolated meniscal repair. The detailed data are shown in Table 1.

In the univariate analysis, we found that those patients who underwent meniscus repair within one month after meniscus tear were more likely to need fewer sutures than those who underwent surgery more than one month after injury (70/110 versus $59 / 115, p=0.062)$. In

Table 1 Demographic baseline data

\begin{tabular}{|c|c|c|c|}
\hline & $\leq 2$ sutures & $>2$ sutures & $P$-value \\
\hline Gender & & & 0.603 \\
\hline Male & 98 & 70 & \\
\hline Female & 31 & 26 & \\
\hline Age & & & 1.000 \\
\hline$\leq 40$ & 112 & 83 & \\
\hline$>40$ & 17 & 13 & \\
\hline Weight & & & 0.637 \\
\hline$\leq 60$ & 20 & 15 & \\
\hline $60-90$ & 96 & 65 & \\
\hline$\geq 90$ & 13 & 13 & \\
\hline Site of tear & & & 0.620 \\
\hline Multiple & 11 & 8 & \\
\hline Anterior & 2 & 1 & \\
\hline Body & 8 & 2 & \\
\hline Posterior & 77 & 57 & \\
\hline$A C L$ injury & & & 0.311 \\
\hline Yes & 105 & 83 & \\
\hline No & 24 & 13 & \\
\hline Duration of injury & & & 0.062 \\
\hline$\leq 1$ month & 70 & 40 & \\
\hline$>1$ month & 59 & 56 & \\
\hline Side of meniscis & & & 0.003 \\
\hline Lateral & 75 & 34 & \\
\hline Medial & 34 & 38 & \\
\hline Both & 20 & 24 & \\
\hline Surgeons & & & 0.311 \\
\hline 1 & 58 & 45 & \\
\hline 2 & 41 & 23 & \\
\hline 3 & 30 & 28 & \\
\hline
\end{tabular}

total, 75/109 (68.8\%) lateral meniscal tears were repaired with fewer sutures than medial $(34 / 72,47.2 \%)$ and bilateral tears $(20 / 44,45.4 \% ; p=0.003)$. In the multivariate analysis, we found that the duration of injury (OR, 2.06; 95\% CI, 1.16-3.64, $p=0.013$ ), presence of an ACL injury (OR, 3.76; 95\% CI, 1.97-7.21, $p<0.001$ ) and the side of the meniscus (OR, 0.31; 95\% CI, 0.14-0.65, $p=0.002$ ) were associated with the number of sutures used during the meniscal repair procedure (Table 2).

\section{Discussion}

Many articles have demonstrated that the loss of meniscal tissue can lead to early onset of degenerative knee joint changes in the long term. Verdonk et al. [15] and Hall et al. [16] claimed that the removal of $30 \%$ of meniscal tissue may increase joint surface contact forces by approximately $300 \%$. Thus, a consensus has been reached that meniscal tissue should be preserved as much as possible $[1,7,8]$. The already popularized method to preserve meniscal tissue is the arthroscopic meniscus repair procedure.

With the development of meniscal repair surgery, many suture devices and techniques have been used [17, 18]. Several studies have been performed to investigate the clinical outcomes with different suture materials and repair techniques and have shown that the results are comparable with regard to the patient-reported outcomes and meniscal healing rate [19-21]. In our study, we used the FasT-Fix suture device for all patients with all-inside meniscal repair, which is the most widely used procedure. However, the FasT-Fix device is expensive. One of the most common questions that patients ask before surgery is how much they need to pay for the operation. However, that cannot be answered accurately, as the surgical cost is associated with the number of sutures. Furthermore, the number of sutures indirectly reflect the length of meniscal tears which have been showed to be a predicting factor of clinical prognosis [2, 13]. In some studies, authors demonstrated that length of meniscal tear less than $2 \mathrm{~cm}$ is a predicting factor for a lower failure rate [13]. John et al. [12] performed a study to investigate the risk factors associated with high failure rate of meniscal repair and found that patients with a greater number of sutures (2.97 sutures) are more likely to have a lower failure rate comparing those with a small number of sutures (1.79 sutures). Given the

Table 2 Multivariable analysis of factors associated with the number of sutures

\begin{tabular}{llll}
\hline & Regression coefficient & $\mathbf{9 5 \% C l}$ & $\boldsymbol{P}$-value \\
\hline Duration of injury & 2.06 & 1.16 to 3.64 & 0.013 \\
Side of meniscis & 0.31 & 0.14 to 0.65 & 0.002 \\
\hline
\end{tabular}


important clinical significance of the number of sutures, we implemented this study.

In the current study, we found that patients who underwent meniscal repair within one month after meniscus tear were more likely to use few sutures. The meniscus is an important second stabilizer of the knee joint. When it tears, especially in those patients with ACL deficiency, the knee is unstable [22, 23]. The meniscus becomes susceptible to additional force, particularly when surgery is delayed, and the incidence of subsequent meniscal and chondral lesions is significantly increased, which has been reported in a large number of studies [22, 24, 25]. Consequently, a serious meniscal tears, such as bucket-handle tears or long meniscal posterior root tears tend to consume a larger number of sutures. Additionally, our findings provide further evidence for the opinion that meniscal repair should be performed early.

Theoretically, medial menisci are more vulnerable to shear forces than lateral menisci. Because the medial meniscus is attached to the medial collateral ligament, its mobility is much smaller than that of the lateral meniscus, which may subsequently increase the severity of meniscal tears [26, 27]. Additionally, for most patients, arthroscopic surgery was delayed, which has been confirmed to be a potential risk factor for increased meniscal injury, especially in those patients with concomitant ACL rupture. Lateral meniscus tears are not associated with the injury-to-surgery interval [24]. The above two reasons may explain why the medial meniscus is more likely to need more sutures to be repaired.

Our results demonstrated that lateral meniscus injury and performing operations within one month after injury tend to require fewer suture devices. To our knowledge, this is the first study to investigate the risk factors that can increase the use of suture devices. We hope that identifying factors that are associated with the number of sutures used during meniscal repair can help surgeons to make surgical planning preoperatively. Besides, on the promise of having a good clinical outcomes, avoiding these risk factors, such as performing meniscal repair surgery within one month after meniscus injury, may have an influence on clinical prognosis.

However, our study has some limitations. First, this study was conducted based on data from a single medical center in China. We are not sure whether our findings can be generalized to the general orthopedic population in other hospitals. Nevertheless, we hope this study can provoke attention and thinking about what factors are associated with the use of a large number of sutures. Finally, all arthroscopic meniscal repairs were performed by three different highly experienced surgeons; thus, option bias may exist. However, we believe this study reflects realistic clinical issues.

\section{Conclusion}

Those patients who underwent meniscal repair within one month after meniscus tear, especially lateral menisci tears, were more likely to need fewer suture devices.

\section{Abbreviations \\ ACL: Anterior cruciate ligament; BMI: Body mass index; MRI: Magnetic resonance imaging}

\section{Acknowledgements}

None

Authors' contributions

XXS participated in the design of the study, wrote the manuscript and performed the study, CWX and XXS collected and analyzed the data. DYC and QJ and XSQ designed and supervised the entire study. XXS was a major contributor in writing the manuscript. All authors read and approved the final manuscript.

\section{Funding}

$\mathrm{NO}$

\section{Availability of data and materials}

The datasets used and/or analyzed during the current study will be available from author XXS on a reasonable request and no material or illustrations have been previously published.

Ethics approval and consent to participate

No patients' private information is involved. Therefore ethics approval is not needed from our Research Ethics Committee and consent for participation was waived

Consent for publication

Not applicable.

\section{Competing interests}

The authors declare that no benefits in any form have been received or will be received from a commercial party related directly or indirectly to the subject of this article.

\section{Author details}

${ }^{1}$ Department of Orthopedics, Affiliated Taikang Xianlin Drum Tower Hospital, Medical School of Nanjing University, Nanjing, Jiangsu, People's Republic of China. ${ }^{2}$ Department of Sports Medicine and Adult Reconstructive Surgery, Nanjing Drum Tower Hospital, School of Medicine, Nanjing University, 321 Zhongshan Road, Nanjing 210008, Jiangsu, People's Republic of China.

Received: 5 September 2020 Accepted: 23 December 2020

Published online: 12 January 2021

References

1. Fuchs A, Kloos F, Bode G, Izadpanah K, Sudkamp NP, Feucht MJ. Isolated revision meniscal repair - failure rates, clinical outcome, and patient satisfaction. BMC Musculoskelet Disord. 2018;19(1):446.

2. Matsushita T, Nagai K, Araki D, Tanaka T, Matsumoto T, Nishida K, Kurosaka $M$, Kuroda R. Factors associated with the status of meniscal tears following meniscal repair concomitant with anterior cruciate ligament reconstruction. Connect Tissue Res. 2017:58(3-4):386-92.

3. Karia M, Ghaly Y, Al-Hadithy N, Mordecai S, Gupte C. Current concepts in the techniques, indications and outcomes of meniscal repairs. Eur J Orthop Surg Traumatol. 2019;29(3):509-20.

4. Yim JH, Seon JK, Song EK, Choi Jl, Kim MC, Lee KB, Seo HY. A comparative study of meniscectomy and nonoperative treatment for degenerative horizontal tears of the medial meniscus. Am J Sports Med. 2013;41(7):1565-70. 
5. Svantesson E, Cristiani R, Hamrin Senorski E, Forssblad M, Samuelsson K, Stalman A. Meniscal repair results in inferior short-term outcomes compared with meniscal resection: a cohort study of 6398 patients with primary anterior cruciate ligament reconstruction. Knee Surg Sports Traumatol Arthrosc. 2018;26(8):2251-8.

6. Haviv B, Bronak S, Kosashvili Y, Thein R. Which patients are less likely to improve during the first year after arthroscopic partial meniscectomy? A multivariate analysis of 201 patients with prospective follow-up. Knee Surg Sports Traumatol Arthrosc. 2016;24(5):1427-31.

7. Zimmerer A, Sobau C, Nietschke R, Schneider M, Ellermann A. Long-term outcome after all inside meniscal repair using the FasT-fix system. J Orthop. 2018;15(2):602-5.

8. Billieres J, Pujol N, the UCoE. Meniscal repair associated with a partial meniscectomy for treating complex horizontal cleavage tears in young patients may lead to excellent long-term outcomes. Knee Surg Sports Traumatol Arthrosc. 2019;27(2):343-8.

9. Kramer DE, Kalish LA, Martin DJ, Yen YM, Kocher MS, Micheli LJ, Heyworth BE. Outcomes after the operative treatment of bucket-handle meniscal tears in children and adolescents. Orthop J Sports Med. 2019;7(1): 2325967118820305

10. Beaufils P, Pujol N. Meniscal repair: Technique. Orthop Traumatol Surg Res. 2018;104(1S):S137-45.

11. Yoon KH, Park JY, Kwon YB, Lee YJ, Kim EJ, Kim SG. Inside-out repair of the meniscus in concomitant anterior cruciate ligament reconstruction: absorbable versus nonabsorbable sutures. Arthroscopy. 2020;36(4):1074-82.

12. Schlechter JA, Nguyen SV, Fletcher KL. Meniscal repairs in the adolescent knee: can the number of fixation sites improve outcomes? Orthop J Sports Med. 2019;7(11):2325967119881963.

13. Yeo DYT, Suhaimi F, Parker DA. Factors predicting failure rates and patientreported outcome measures after arthroscopic meniscal repair. Arthroscopy. 2019;35(11):3146-64 e3142.

14. Song X, Li Q, Wu Z, Xu Q, Chen D, Jiang Q. Predicting the graft diameter of the peroneus longus tendon for anterior cruciate ligament reconstruction. Medicine (Baltimore). 2018;97(44):e12672.

15. Verdonk R, Madry H, Shabshin N, Dirisamer F, Peretti GM, Pujol N, Spalding T, Verdonk P, Seil R, Condello V, et al. The role of meniscal tissue in joint protection in early osteoarthritis. Knee Surg Sports Traumatol Arthrosc. 2016; 24(6):1763-74

16. Sturnieks DL, Besier TF, Mills PM, Ackland TR, Maguire KF, Stachowiak GW, Podsiadlo P, Lloyd DG. Knee joint biomechanics following arthroscopic partial meniscectomy. J Orthop Res. 2008;26(8):1075-80.

17. Solheim E, Hegna J, Inderhaug E. Long-term outcome after all-inside meniscal repair using the RapidLoc system. Knee Surg Sports Traumatol Arthrosc. 2016;24(5):1495-500.

18. Ardizzone CA, Houck DA, McCartney DW, Vidal AF, Frank RM. All-inside repair of bucket-handle meniscal tears: clinical outcomes and prognostic factors. Am J Sports Med. 2020;48(13):3386-93. https://doi.org/10.1177/ 0363546520906141.

19. Kang DG, Park YJ, Yu JH, Oh JB, Lee DY. A systematic review and metaanalysis of arthroscopic meniscus repair in young patients: comparison of all-inside and inside-out suture techniques. Knee Surg Relat Res. 2019;31(1):1-11.

20. Buckley PS, Kemler BR, Robbins CM, Aman ZS, Storaci HW, Dornan GJ, LaPrade RF. Biomechanical comparison of 3 novel repair techniques for radial tears of the medial meniscus: the 2-tunnel Transtibial technique, a "hybrid" horizontal and vertical mattress suture configuration, and a combined "hybrid tunnel" technique. Am J Sports Med. 2019;47(3):651-8.

21. Nakama GY, Aman ZS, Storaci HW, Kuczmarski AS, Krob JJ, Strauss MJ. Different suture materials for arthroscopic Transtibial pull-out repair of medial meniscal posterior root tears: a human biomechanical study. Orthop J Sports Med. 2019;7(9):2325967119873274.

22. Stone JA, Perrone GS, Nezwek TA, Cui Q, Vlad SC, Richmond JC, Salzler MJ. Delayed $A C L$ reconstruction in patients $>/=40$ years of age is associated with increased risk of medial meniscal injury at 1 year. Am J Sports Med. 2019;47(3):584-9.

23. Chen $\mathrm{KH}$, Chiang ER, Wang HY, Ma HL. Correlation of meniscal tear with timing of anterior cruciate ligament reconstruction in patients without initially concurrent meniscal tear. J Knee Surg. 2019;32(11):1128-32.

24. Everhart JS, Kirven JC, Abouljoud MM, DiBartola AC, Kaeding CC, Flanigan DC. Effect of delayed primary anterior cruciate ligament reconstruction on medial compartment cartilage and meniscal health. Am J Sports Med. 2019; 47(8):1816-24.

25. Taketomi S, Inui H, Yamagami R, Kawaguchi K, Nakazato K, Kono K, Kawata M, Nakagawa T, Tanaka S. Surgical timing of anterior cruciate ligament reconstruction to prevent associated meniscal and cartilage lesions. J Orthop Sci. 2018;23(3):546-51.

26. Lau BC, Conway D, Mulvihill J, Zhang AL, Feeley BT. Biomechanical consequences of meniscal tear, partial Meniscectomy, and meniscal repair in the knee. JBJS Rev. 2018;6(4):e3.

27. Abram SGF, Beard DJ, Price AJ, Group BMW. National consensus on the definition, investigation, and classification of meniscal lesions of the knee. Knee. 2018;25(5):834-40.

\section{Publisher's Note}

Springer Nature remains neutral with regard to jurisdictional claims in published maps and institutional affiliations.
Ready to submit your research? Choose BMC and benefit from:

- fast, convenient online submission

- thorough peer review by experienced researchers in your field

- rapid publication on acceptance

- support for research data, including large and complex data types

- gold Open Access which fosters wider collaboration and increased citations

- maximum visibility for your research: over $100 \mathrm{M}$ website views per year

At BMC, research is always in progress.

Learn more biomedcentral.com/submissions 